\title{
ESFERA PÚBLICA E DEMOCRACIA DELIBERATIVA EM HABERMAS Modelo teórico e discursos críticos
}

\author{
Jorge Adriano Lubenow ${ }^{l}$ \\ lubenow@ufpi.edu.br
}

RESUMO Os argumentos a favor da concepção deliberativa de esfera pública e democracia têm sido alvos de muitas críticas. Muitos teóricos que se ocupam com teorias democráticas têm questionado as assunções básicas da teoria política deliberativa que resulta da obra sobre Faktizität und Geltung (1992), apontando pontos frágeis, sobre as implicações práticas, possibilidades de efetividade, entre outros. Embora não seja possivel acompanhar em toda sua amplitude a bibliografia crítica sobre o tema, para nossos propósitos, vamos aqui nos limitar a apresentar alguns comentários acerca das controvérsias envolvendo as concepções de esfera pública e democracia deliberativa que resultam da obra sobre direito e democracia; questões que se tornaram problemáticas para a literatura e que poderiam ser melhor investigadas.

Palavras-Chave Jürgen Habermas, Esfera pública, Democracia deliberativa, Discursos críticos

\begin{abstract}
The arguments about the deliberative conception of democracy and public sphere have been largely criticized. Many theorists who deal with democratic theories have questioned the basic assumptions of the deliberative policy theory, which results from Habermas'work Faktizität und Geltung (1992), pointing some weakness of practical implications,
\end{abstract}


opportunities of effectiveness, among others. Although it is almost impossible following the critical literature about the theme in its whole extent, for our purposes, we will just present a few comments about the controversies involving the conceptions of public sphere and deliberative democracy, which stem from works related to democracy and the law; issues that have become not just problematic for literature but that could also be better investigated.

Keywords Jürgen Habermas, Public sphere, Deliberative democracy, Critical comments

\section{A concepção de democracia deliberativa}

Na obra de Habermas Faktizität und Geltung, ${ }^{2}$ os desdobramentos acerca da concepção de democracia recebem um detalhamento mais apurado do papel da esfera pública e sua penetração mais efetiva sobre o político, traduzido numa ênfase na institucionalização. $\mathrm{O}$ exame dos processos institucionais também é uma investigação mais sistemática acerca do potencial político do discurso, e uma outra tentativa, mais realista, de responder a questão sobre a ação recíproca entre solidariedade sociointegrativa do mundo da vida com os procedimentos no nível político e administrativo. Esta investigação mais sistemática é também uma estratégia habermasiana de responder às críticas e mostrar que a Theorie des kommunikativen Handelns ${ }^{3}$ não é cega para a realidade das instituições. ${ }^{4} \mathrm{~A}$ reformulação da relação entre sistema e mundo da vida prepara o caminho para um novo modelo de circulação do poder político (1.1) que tem como central a concepção procedimental deliberativa de democracia (1.2).

1.1 Mundo da vida e sistema: novo modelo de circulação do poder

As críticas à imprecisão das implicações institucionais da concepção habermasiana de esfera pública da Theorie... levam Habermas a sinalizar para uma reformulação da relação sistema-mundo da vida, com a necessidade de um "duplo fluxo", capaz de revigorar as instituições. A ideia de "sitiamento"

2 Originalmente publicada em 1992 pela Suhrkamp Verlag. Tradução: Direito e democracia: entre facticidade e validade. Rio de Janeiro: Tempo Brasileiro, 1997.

3 Originalmente publicada em 1981 pela Suhrkamp Verlag. Tradução: Teoría de la acción comunicativa. Madrid: Taurus, 1987.

4 HABERMAS, Faktizität und Geltung, p. 11. "Ceticismo institucional da Theorie que seria superado em Faktizität und Geltung" (KANTNER; TIETZ. Dialektik, Dialog und Institutionskritik. In: LABERENZ, 2003, p. 127). 
fragiliza a concepção de política que resulta do quadro teórico da Theorie. A concepção de política que resulta da obra sobre a ação comunicativa não permitia uma autodemocratização interna do sistema. Por isso, a perguntachave aqui para Habermas é: "quem revigora as instituições?" Impasse conceitual que obriga Habermas a repensar a articulação entre espontaneidade social e complexidade funcional, o nexo entre poder comunicativo gerado comunicativamente e o poder administrativo formalmente organizado no sistema político.

A partir da segunda metade da década de 80, Habermas introduz mudanças significativas no curso de suas investigações sobre a esfera pública ao voltar a colocar ênfase na questão da institucionalização. ${ }^{5}$ Nesse caminho, reformula a relação sistema-mundo da vida e altera as características da esfera pública, redimensionando-a dentro de um sistema de "eclusas". Em Theorie des kommunikativen Handelns, Habermas tematiza a esfera pública como constitutiva do mundo da vida, responsável por garantir sua autonomia e protegê-lo frente ao sistema administrado. Uma esfera de caráter "defensivo" que, no máximo, poderia "sitiar" o sistema, mas sem grandes pretensões de conquista. Já em Faktizität und Geltung, Habermas confere à esfera pública um caráter mais "ofensivo", abandona a metáfora do "sitiamento" e a substitui adotando o modelo das "eclusas". ${ }^{6}$ Ao reformular a relação entre sistema e mundo da vida, acaba também modificando, não tanto a posição, mas o caráter ofensivo da esfera pública. Sendo assim, onde se localiza e que função desempenha a esfera pública modificada nesse novo modo de ver a ação recíproca entre sistema e mundo da vida?

Na contrapartida ofensiva do novo modelo de circulação do poder político, a categoria de esfera pública é redimensionada dentro deste novo modelo de eclusas e assume um papel mais amplo e mais ativo junto aos processos formais mediados institucionalmente. Com o novo modelo de acoplamento, os processos de comunicação e decisão do sistema político são estruturados através de um sistema de eclusas, no qual os processos de comunicação e decisão já estão ancorados no mundo da vida por uma "abertura estrutural", permitida por uma esfera pública sensível, permeável, capaz de introduzir

5 Cf. prefácio 3aㅡ ed. da Theorie..., 1985.

6 Aqui Habermas acaba optando por reproduzir o cerne do modelo de tomada de decisão de B. Peters, em vez do modelo de um socialismo democrático radical de Nancy Fraser (SCHEUERMAN, William E. Between Radicalism and resignation: democratic theory in Habermas's Between Facts and Norms. In: DEWS, 1999, p. 163). Para Habermas, a concepção das "eclusas" provê mais democratização do que a do sitiamento (Die Normalität einer Berliner Republik, p. 139-140; 152-153). Embora continue em Peters um modelo "representativo", com a diferença de conferir mais qualidade ao procedimento decisório (PETERS, 2001, p. 674, nota 20). 
no sistema político os conflitos existentes na periferia. Agora, o sistema político já não é mais pensado autopoiéticamente, mas constitui um centro poliárquico. Aqui, Habermas reconhece que a imagem de uma fortaleza sitiada democraticamente que aplicou ao Estado nos anos 80 na Theorie... pode induzir ao erro, pois ela não permite uma autodemocratização interna do sistema. ${ }^{7}$ A seguinte passagem deixa claro o abandono da tese do desacoplamento entre sistema e mundo da vida e a formulação de uma concepção diferente de poder e de sistema político em Faktizität und Geltung:

O núcleo do sistema político é formado pelos seguintes complexos institucionais, já conhecidos: a administração (incluindo o governo), o judiciário e a formação democrática da opinião e da vontade (incluindo as corporações parlamentares, eleições políticas, concorrência entre partidos, etc). Portanto, esse centro, que se perfila perante uma periferia ramificada, através de competências formais de decisão e de prerrogativas reais, é formado de modo "poliárquico". No interior do núcleo, a "capacidade de ação" varia, dependendo da "densidade" da complexidade organizatória. O complexo parlamentar é o que se encontra mais aberto para a percepção e a tematização dos problemas sociais [...] Nas margens da administração forma-se uma espécie de periferia interna, que abrange instituições variadas, dotadas de tipos diferentes de direitos de auto-administração ou de funções estatais delegadas, de controle ou de soberania (universidades, sistemas de seguros, representações de corporações, câmaras, associações beneficentes, fundações, etc.). Tomado em seu conjunto, o núcleo possui uma periferia exterior, a qual se bifurca, grosso modo, em compradores e fornecedores. ${ }^{8}$

A contrapartida ofensiva da esfera pública sobre o político assenta na ênfase nos processos de institucionalização. Para Habermas, tal desencadeamento está amarrado a um processo de normatização, que se inicia pela formação da opinião e da vontade nas esferas públicas informais, acaba desaguando, pelo caminho procedimental, nas instâncias formais de deliberação e decisão. Este processo de "abertura” para a institucionalização está ancorado num amplo conceito de democracia procedimental e deliberativa.

\subsection{Democracia deliberativa}

Habermas pode não ter sido o primeiro a escrever sobre "deliberação", mas talvez seja o mais proeminente defensor da teoria deliberativa de democracia. ${ }^{10} \mathrm{Na}$ década de 90 , Habermas coloca forte peso na questão da

7 HABERMAS, Faktizität und Geltung, p. 531.

8 HABERMAS, Faktizität und Geltung, p. 430.

9 Cf. observação de Marcos Nobre. In: NOBRE; COELHO, 2004, p. 34.

10 As investigações de Habermas sobre política deliberativa influenciaram muitas discussões sobre teoria democrática e se estenderam para um vasto campo de discussão. Nesse sentido, note-se que a maior 
"institucionalização". Em Faktizität und Geltung, formula um projeto de institucionalização que se orienta pelo paradigma procedimental de democracia. Com isso, quer resolver o problema de como a formação discursiva da opinião e da vontade pode ser institucionalizada, da ação recíproca entre as esferas informais do mundo da vida com as esferas formais dos processos de tomadas de decisão institucionalizados, de como transformar poder comunicativo em poder administrativo. $\mathrm{O}$ pensamento político habermasiano dirige-se a uma teoria da democracia, agora pensada em termos institucionais. Por isso, a atenção com os pressupostos, os arranjos institucionais, os mecanismos de controle político. Para tanto, Habermas elabora uma teoria da democracia procedimental e deliberativa, a partir do modelo das "eclusas".

A concepção de política deliberativa é uma tentativa de formular uma teoria da democracia a partir de duas tradições teórico-políticas: a concepção de autonomia pública da teoria política republicana (vontade geral, soberania popular), com a concepção de autonomia privada da teoria política liberal (interesses particulares, liberdades individuais). Ela pode ser concebida, simultaneamente, como um meio-termo e uma alternativa aos modelos republicano e liberal. ${ }^{11}$ No entanto, embora o tema geral seja o mesmo, há diferentes visões de democracia deliberativa, que conferem diferentes níveis dos processos democráticos, e modos diferentes de compreender as fronteiras entre a autonomia privada e autonomia pública. Embora não possamos prestar contas aqui das diferenciações internas pormenorizadas dessas diferentes compreensões, há, por um lado, autores que buscam reformular internamente elementos do modelo liberal de democracia, e por outro lado, há aqueles que refutam o paradigma liberal apresentando novas alternativas. ${ }^{12}$ Mas,

parte da literatura sobre democracia deliberativa está datada posteriormente a Faktizität und Geltung (1992).

11 SOUZA, 2000, p. 59.

12 Para bibliografia sobre democracia deliberativa, ver: COHEN, Joshua. Deliberation and Democratic Legitimacy. In: HAMLIN, Alan; PETTIT, Philip (Ed.). The Good Polity: Normative analysis of the State. Oxford/New York: Basil Blackwell, 1989. p. 17-34; FISHKIN, J. Democracy and Deliberation. New Haven: Yale. 1991; BOHMAN, J. Public Deliberation, Compexity, and Democracy. London: MIT Press, 1996; DRYZEK, J. Deliberative Democracy and Beyond. Oxford: Oxford Univ. Press, 2000; FISHKIN, J.; LASLETT, P. Debating Deliberative Democracy. Stuttgart: GB Verlag, 2002; PALAZZO, G. Die Mitte der Demokratie: Über die Theorie deliberativer Demokratie von Jürgen Habermas. Nomos Verlag, 2002. E as coletâneas: BENHABIB, S. Democracy and Difference: Contesting the Boundaries of the Political. Princeton, 1996; BOHMAN, J.; REHG, W. Deliberative Democracy. Cambridge: MIT Press, 1997; ELSTER, J. (Ed.) Deliberative Democracy. Cambridge: Cambridge Univ. Press, 1998; ROSENFELD, M.; ARATO, A. Habermas on Law and Democracy. University of California Press, 1998; GUTMANN, A.; THOMPSON, D. Democracy and Disagreement. Harward Univ. Press, 1994; GASTIL, J.; PETER, L. The Deliberative Democracy Handbook. WJS Verlag, 2005; SCHAAL, Gary; STRECKER, David. Die politische Theorie der Deliberation: Jürgen Habermas. In: BRODOCZ; SCHAAL. Politische Theorien der Gegenwart. Opladen, p. 69-93, (1999); WERLE, Denílson; MELO, R. Democracia deliberativa. Singular, 2007. 
diferentemente de quem rejeita veementemente a tradição liberal, Habermas ainda busca conciliar as tradições liberal e republicana. No entanto, se a teoria deliberativa é uma alternativa frente aos modelos liberal e republicano, o que ela introduz de novo? O modelo deliberativo pode "fazer a diferença"? ${ }^{13}$

"Deliberação" é uma categoria normativa que sublinha uma concepção procedimental de legitimidade democrática, segundo Habermas. Esta concepção normativa gera uma matriz conceitual diferente para definir a natureza do processo democrático, ${ }^{14}$ sob os aspectos regulativos (ou exigências normativas) da publicidade, racionalidade e igualdade. ${ }^{15}$ Embora também tenha um caráter empírico-explicativo, a ênfase da concepção habermasiana de democracia procedimental assenta no caráter crítico-normativo. A concepção procedimental de democracia é uma concepção formal e assenta nas exigências normativas da ampliação da participação dos indivíduos nos processos de deliberação e decisão e no fomento de uma cultura política democrática. Por ser assim, esta concepção está centrada nos procedimentos formais que indicam "quem" participa, e "como" fazê-lo (ou está legitimado a participar ou fazê-lo), mas não diz nada sobre "o que" deve ser decidido. Ou seja, as regras do jogo democrático (eleições regulares, princípio da maioria, sufrágio universal, alternância de poder) não fornecem nenhuma orientação nem podem garantir o "conteúdo" das deliberações e decisões.

Para Habermas, dois modelos normativos de democracia dominaram o debate até aqui, o liberal e o republicano. Diante destes, propõe um modelo alternativo, o procedimental. ${ }^{16} \mathrm{~A}$ dimensão política comparativa tomada pelo autor é a formação democrática da opinião e da vontade. ${ }^{17}$ Além disso, o entendimento distinto do processo democrático carrega também compreensões normativas distintas de estado e sociedade, e para a compreensão da legitimidade e da soberania popular.

13 Sobre a diferença do modelo procedimental em relação aos outros modelos, ver: HABERMAS, Jürgen. Faktizität und Geltung, p. 363 et seq.; HABERMAS, Drei normative Modelle der Demokratie. In: HABERMAS, Jürgen. Die Einbeziehung des Anderen, p. 277-292 [Ver cap. 5, "Was heißt Deliberativer Politik"]; HABERMAS, Jürgen. Three Models of Democracy. Constellations, v. 1, v. 1, p. 1-10, 1994. Para a discussão Habermas-Rawls, ver: The Journal of Philosophy, XCII, n. 3, 1995. Além disso, ver: HELD, David. Models of Democracy. Standford: Standford University Press, 1987; GUTMANN; THOMPSON. Why Deliberative Democracy is Different? Social Philosophy \& Policy, 17, p. 161-180, 2000; BENHABIB, Seyla. Deliberative Rationality and Models of Democratic Legitimacy. Constellations, 1, p. 26-52, 1994; COOKE, Maeve. Five Arguments for Deliberative Democracy. Political Studies, 48, p. 947-969, 2000; NOBRE, Marcos. Participação e deliberação na teoria democrática: uma introdução. In: NOBRE; COELHO. Participação e Deliberação. 2004. p. 31-37; WERLE, Denílson; MELO, Rúrion. Democracia deliberativa. São Paulo: Singular, 2007.

14 HABERMAS. Drei normative Modelle der Demokratie, p. 277.

15 HABERMAS. Political Communication in Media Society, p. 4.

16 HABERMAS. Drei normative Modelle der Demokratie, p. 277.

17 HABERMAS. Drei normative Modelle der Demokratie, p. 285. 
No modelo liberal, o processo democrático tem por objetivo intermediar a sociedade (um sistema estruturado segundo as leis do mercado, interesses privados) e o Estado (como aparato da administração pública). Nesta perspectiva, a política tem a função de agregar interesses sociais e os impor ao aparato estatal; é essencialmente uma luta por posições que permitam dispor de poder administrativo, uma autorização para que se ocupem posições de poder. O processo de formação da vontade e da opinião política é determinado pela concorrência entre agentes coletivos agindo estrategicamente em manter ou conquistar posições de poder. Por esse modo, esta compreensão de política opera com um conceito de sociedade centrado no Estado (como cerne do poder político). Como não é possível eliminar a separação entre Estado e sociedade, visa-se superá-la apenas via processo democrático. No entanto, a conotação normativa de equilíbrio de poder e interesses é frágil e precisa ser complementada estatal e juridicamente. Mas ela se orienta pelo lado output da avaliação dos resultados da atividade estatal. O êxito em tal processo é medido pela concordância dos cidadãos em relação a pessoas e programas, quantificado em votos. ${ }^{18}$

No modelo republicano, o processo democrático vai além dessa função mediadora. Apresenta a necessidade de uma formação da opinião e da vontade e da solidariedade social que resulte da reflexão e conscientização dos atores sociais livres e iguais. Nessa perspectiva, a política não obedece aos procedimentos do mercado, mas às estruturas de comunicação pública orientada pelo entendimento mútuo, configuradas num espaço público. Este exercício de auto-organização da sociedade pelos cidadãos por via coletiva seria capaz de emprestar força legitimadora ao processo político. Por esse viés, da auto-organização política da sociedade, esta compreensão de política republicana opera com um conceito de sociedade direcionado contra o Estado (sociedade é o cerne da política). Orienta-se pelo input de uma formação da vontade política. ${ }^{19}$

O modelo deliberativo, por sua vez, acolhe elementos de ambos os lados e os integra de uma maneira nova e distinta num conceito de procedimento ideal para deliberações e tomadas de decisão. Esta compreensão do processo democrático tem conotações normativas mais fortes que o modelo liberal, mas menos normativas do que o modelo republicano. Como o republicanismo, a teoria discursiva da democracia reserva uma posição central ao processo político de formação da opinião e da vontade, entretanto sem entender como 
algo secundário à constituição jurídico-estatal. ${ }^{20}$ Como o modelo liberal, também na teoria discursiva da democracia os limites entre Estado e sociedade são respeitados. Todavia, aqui, a sociedade civil, como base social das opiniões públicas autônomas, distingue-se tanto dos sistemas de ação econômicos quanto da administração pública. Dessa compreensão do procedimento democrático resulta normativamente a exigência de um deslocamento dos pesos que se aplicam a cada um dos elementos na relação entre os três recursos, a saber, dinheiro, poder administrativo e solidariedade, a partir das quais as sociedades modernas preenchem sua necessidade de integração e de regulação. As implicações normativas são evidentes: a força sociointegrativa da solidariedade, que não pode mais ser obtida, mas ser extraída apenas das fontes da ação comunicativa, precisa desenvolver-se em espaços públicos autônomos diversos e procedimentos de formação democrática da opinião e da vontade política institucionalizados jurídico-estatalmente; e ser capaz de se afirmar contra os outros dois poderes, dinheiro e poder administrativo. ${ }^{21}$

O princípio procedimental da democracia visa amarrar um procedimento de normatização (o que significa: um processo de institucionalização da formação racional da opinião e da vontade), através do caráter procedimental, que garante formalmente igual participação em processos de formação discursiva da opinião e da vontade e estabelece, com isso, um procedimento legítimo de normatização. Nesse caminho via procedimento e deliberação, que constitui o cerne do processo democrático, pressupostos comunicativos de formação da opinião e da vontade funcionam como a "eclusa" mais importante para a racionalização discursiva das decisões no âmbito institucional. Procedimentos democráticos proporcionam resultados racionais na medida em que a formação da opinião e da vontade institucionalizada é sensível aos resultados de sua formação informal da opinião que resulta das esferas públicas autônomas e que se formam ao seu redor. As comunicações públicas, oriundas das redes periféricas, são captadas e filtradas por associações, partidos e meios de comunicação, e canalizadas para os foros institucionais de resolução e tomadas de decisão:

A chave da concepção procedimental de democracia consiste precisamente no fato de que o processo democrático institucionaliza discursos e negociações com o auxílio de formas de comunicação às quais devem fundamentar a suposição de racionalidade para todos os resultados obtidos conforme o processo. ${ }^{22}$

20 HABERMAS. Drei normative Modelle der Demokratie, p. 287.

21 HABERMAS. Drei normative Modelle der Demokratie, p. 288-289.

22 HABERMAS, 1992, p 368. 
Como se vê nessa passagem, do ponto de vista normativo, o que empresta força legitimadora ao "procedimento" é justamente o percurso ou a base argumentativa de fundamentação discursiva que se desenrola na esfera pública. Este percurso visa garantir o uso equitativo das liberdades comunicativas, conferindo por esse modo também força legitimadora ao processo de normatização. Ou seja, a compreensão procedimental de democracia tenta mostrar que os pressupostos comunicativos e as condições do processo de formação da opinião são a única fonte de legitimação; que a formação democrática da opinião e da vontade tira sua força legitimadora dos pressupostos comunicativos e dos procedimentos democráticos. Procedimentos que fundamentam uma medida para a legitimidade da influência exercida por opiniões públicas sobre a esfera formal do sistema político. Para serem legítimas, as decisões têm que ser reguladas por fluxos comunicativos que partem da periferia e atravessam as comportas dos procedimentos próprios à democracia. A própria pressão da esfera pública consegue forçar a elaboração de questões e, com isso, atualizar sensibilidades em relação às responsabilidades políticas. ${ }^{23}$

Na perspectiva de uma teoria da democracia, a esfera pública tem que reforçar a pressão exercida pelos problemas, ou seja, ela não pode limitar-se a percebê-los, e a identificá-los, devendo, além disso, tematizá-los, problematizá-los e dramatizá-los de modo convincente e eficaz, a ponto de serem assumidos e elaborados pelo complexo parlamentar. $^{24}$

\section{A concepção de esfera pública deliberativa}

Não há dúvidas de que a concepção normativa da esfera pública "deliberativa" formulada em Faktizität und Geltung (1992) significa uma reorientação do foco teórico em relação às formulações anteriores, especialmente em Strukturwandel der Öffentlichkeit (1962), Theorie des Kommunikativen Handelns (1982), e no "prefácio" à nova edição de Strukturwandel der Öffentlichkeit (publicada em 1990). O novo papel da esfera pública dentro de uma teoria deliberativa da democracia enfatiza ainda mais a ampliação da categoria esfera pública, já esboçada no "prefácio" de 1990, mas agora com uma influência mais efetiva nos contextos formais e institucionalizados de deliberação e decisão políticos. ${ }^{25} \mathrm{O}$ que interessa

25 Além da racionalização do poder, agora também uma racionalização da economia. Entretanto, um agir mais efetivo permaneceu apenas no campo político. A esfera da economia continuou sem intervenção. 
esclarecer aqui é: qual a especificidade da categoria de esfera pública em Faktizität und Geltung?

$\mathrm{Na}$ linguagem habermasiana, o procedimento da democracia deliberativa constitui o âmago do processo democrático. ${ }^{26} \mathrm{~A}$ esfera pública, por sua vez, é a categoria normativa chave do processo político deliberativo habermasiano. A esfera pública é uma "estrutura intermediária" que faz a mediação entre o Estado e o sistema político e os setores privados do mundo da vida. ${ }^{27}$ Uma "estrutura comunicativa", um centro potencial de comunicação pública, que revela um raciocínio de natureza pública, de formação da opinião e da vontade política, enraizada no mundo da vida através da sociedade civil. A esfera pública tem a ver com o "espaço social" do qual pode emergir uma formação discursiva da opinião e da vontade política. ${ }^{28}$ No seu bojo colidem os conflitos em torno do controle dos fluxos comunicativos que percorrem o limiar entre o mundo da vida e a sociedade civil e o sistema político e administrativo. A esfera pública constitui uma "caixa de ressonância", ${ }^{29}$ dotada de um sistema de sensores sensíveis ao âmbito de toda sociedade, ${ }^{30} \mathrm{e} \mathrm{tem} \mathrm{a} \mathrm{função} \mathrm{de} \mathrm{filtrar} \mathrm{e}$ sintetizar temas, argumentos e contribuições, e transportá-los para o nível dos processos institucionalizados de resolução e decisão, de introduzir no sistema político os conflitos existentes na sociedade civil, a fim de exercer influência e direcionar os processos de regulação e circulação do poder do sistema político, ${ }^{31}$ através de uma abertura estrutural, sensível e porosa, ancorada no mundo da vida. ${ }^{32}$

Esfera ou espaço público é um fenômeno social elementar do mesmo modo que a ação, o ator, o grupo ou a coletividade; porém, ele não é arrolado entre os conceitos tradicionais elaborados para descrever a ordem social. A esfera pública não pode ser entendida como uma instituição, nem como uma organização, pois ela constitui uma estrutura normativa capaz de diferenciar entre competências e papéis, nem regula o modo de pertença a uma organização, etc. Tampouco ela constitui um sistema, pois mesmo que seja possível delinear seus limites internos, exteriormente ela se caracteriza através de horizontes abertos, permeáveis e deslocáveis. A esfera pública

Na verdade, ela continua a ser indireta. Faz-se via política, que pode estabelecer regulações na economia. Para comentários críticos, ver: "The public sphere, civil society, and the rule of capital". In: MARSH, James Unjust Legality. A Critique of Habermas's Philosophy of Law. Rowman \& Littlefield Publishers, 2001. p. 123-152; The Limitations of Habermas's Social and Political Argument. In: SITTON, John. Habermas and Contemporary Society. Palgrave, 2003. p. 121-140.

26 HABERMAS, 1992, p. 359.

27 HABERMAS, 1992, p. 451.

28 HABERMAS, 1992, p. 436.

29 HABERMAS, 1992, p. 400; 417.

30 HABERMAS, 1992 , p. 364.

31 HABERMAS, 1992 , p. 364; 398; 435; 532-533.

32 HABERMAS, 1992, p. 429-30. 
pode ser descrita como uma rede adequada para a comunicação de conteúdos, tomadas de posição e opiniões; nela os fluxos comunicativos são filtrados e sintetizados, a ponto de se condensarem em opiniões públicas enfeixadas em temas específicos. Do mesmo modo que o mundo da vida tomado globalmente, a esfera pública se reproduz através do agir comunicativo, implicando apenas o domínio de uma linguagem natural; ela está em sintonia com a compreensibilidade geral da prática comunicativa cotidiana. Descobrimos que o mundo da vida é um reservatório para intenções simples; e os sistemas de ação e de saber especializados, que se formam no interior do mundo da vida, continuam vinculados a ele. Eles se ligam a funções gerais de reprodução do mundo da vida (como é o caso da religião, da escola e da família), ou a diferentes aspectos de validade do saber comunicado através da linguagem comum (como é o caso da ciência, da moral e da arte). Todavia, a esfera pública não se especializa em nenhuma destas direções; por isso, quando abrange questões politicamente relevantes, ela deixa ao cargo do sistema político a elaboração especializada. A esfera pública constitui principalmente uma estrutura comunicativa do agir orientado pelo entendimento, a qual tem a ver com o espaço social gerado no agir comunicativo, não com as funções nem com os conteúdos da comunicação cotidiana. $^{33}$

No entanto, apesar dessa definição mais geral, como determinar qual a sua especificidade, fixar a extensão ou os limites internos e externos, estabelecer o que está dentro e o que está fora? Senão vejamos essa outra passagem:

Ela [a esfera pública] representa uma rede supercomplexa que se ramifica num sem número de arenas internacionais, nacionais, regionais, comunais e sub-culturais, que se sobrepõem umas às outras; essa rede se articula objetivamente de acordo com pontos de vista funcionais, temas círculos, etc., assumindo a forma de esferas públicas mais ou menos especializadas, porém, ainda acessíveis a um público de leigos (por exemplo, esferas públicas literárias, eclesiásticas, artísticas, feministas, ou ainda, esferas públicas "alternativas" da política de saúde, da ciência e de outras); além disso, ela se diferencia por níveis, de acordo com a densidade da comunicação, da complexidade organizacional e do alcance, formando três tipos de esfera pública: esfera pública episódica (bares, cafés, encontros de rua), esfera pública da presença organizada (encontros de pais, público que freqüenta teatro, concertos de rock, reuniões de partidos ou congressos de igrejas) e esfera pública abstrata, produzida pela mídia (leitores, ouvintes e espectadores singulares e espalhados globalmente). Apesar dessas diferenciações, as esferas públicas parciais, constituídas através da linguagem comum ordinária, são porosas, permitindo a ligação entre elas. Limites sociais internos decompõem o "texto" da esfera pública, que se estende radicalmente em todas as direções [...] No interior da esfera pública geral, definida através de sua relação com o sistema político, as fronteiras não são rígidas em princípio. ${ }^{34}$

Estas duas passagens acima são elucidativas aqui e sintetizam o estatuto normativo da categoria de esfera pública deliberativa, formulado na obra sobre 
direito e democracia. A esfera pública tem como característica elementar ser um espaço irrestrito de comunicação e deliberação pública, que não pode ser anteriormente estabelecido, limitado ou restringido, os elementos constitutivos não podem ser antecipados. Em princípio, está aberta para todo âmbito social. Não existem temas ou contribuições a priori englobados ou excluídos. A esfera pública é sempre indeterminada quanto aos conteúdos da agenda política e aos indivíduos e grupos que nela podem figurar. É por isso que Habermas não quer (nem pode) descrever, precisamente, quais as linhas internas e externas, quais as fronteiras da esfera pública, embora necessite, por outro lado, de certa autolimitação, para, por exemplo, não ficar a mercê de toda e qualquer forma de manifestação pública (como formas de comunicação estratégicas). Esse é o duplo caráter constitutivo da esfera pública, pelo qual ela acaba oscilando entre a exigência de livre participação e circulação de temas e contribuições e certa autolimitação. ${ }^{35}$ Para tanto, Habermas propõe a adoção da ideia procedimental de deliberação pública, pela qual os "contornos" da esfera pública se forjam durante os processos de identificação, filtragem e interpretação acerca de temas e contribuiçõos que emergem das esferas públicas autônomas e são conduzidos para os foros formais e institucionalizados do sistema político e administrativo. ${ }^{36}$ É nesse caráter procedimental de justificação da legitimidade que se realiza a normatividade da esfera pública. ${ }^{37}$ É da interrelação entre as esferas públicas informais e a esfera pública formal - qual seja, dos fluxos comunicativos e influências públicas que emergem das esferas públicas informais, autônomas, e são transformados em poder comunicativo e transportados para a esfera formal -, que deriva a expectativa normativa da esfera pública.

A expectativa normativa [...] se funda no jogo que se estabelece entre a formação política da vontade, constituída institucionalmente, e os fluxos comunicativos espontâneos de uma esfera pública não organizada e não programada para tomar

35 Sobre essa dual politics, ver: COHEN; ARATO, 1992, p. 460 et seq.; DEMIROVIC, 1994, p. 689.

36 Com isso, Habermas quer resolver também um problema que já aparecia na obra seminal da esfera pública de 1962. O poder da sociedade civil não pode ser associado à ideia de um povo concreto que tem no Estado sua corporificação institucional (a contraparte institucional da sociedade civil) - influência direta no institucional que caracteriza a concepção republicana de soberania popular (como acontecia na obra de 1962). Esta influência precisa ser mediada, se dar através de "meios", precisa ser "procedimentalizada". Sobre isso, ver: AVRITZER, Leonardo. Além da dicotomia estado/mercado: Habermas, Cohen e Arato. Novos Estudos Cebrap, n. 36, 1993.

37 REGH; BOHMAN. Discourse and Democracy: the formal and informal bases of legitimacy in 'Between facts and Norms'. In: BAYNES \& SCHOMBERG. Discourse and Democracy. New York: State University Press, 2002. p. 31-60. 
decisões, os quais não são absorvidos pelo poder. Neste contexto, a esfera pública funciona como uma categoria normativa. ${ }^{38}$

Mas como se dá especificamente esse engate das esferas públicas informais com a esfera pública formal? Segundo Habermas, através de diferentes níveis da esfera pública, como a formação informal da opinião nas esferas públicas informais, nas associações, no interior dos partidos, participação em eleições gerais, corporações parlamentares e governo. ${ }^{39}$ Para tanto, há uma necessidade de complementar a formação da opinião e da vontade parlamentar e dos partidos, através de uma formação informal da opinião e da vontade na esfera pública. Mas, apesar de possuir este aspecto formal, de conduzir à institucionalização via partidos, eleições e outros foros, a esfera pública não é institucionalizada, nem é sistêmica: "A esfera pública não pode ser entendida como uma instituição [...] Tampouco ela constitui um sistema, pois, mesmo que seja possivel delinear seus limites internos, exteriormente ela se caracteriza através de horizontes abertos, permeáveis e deslocáveis". ${ }^{40}$

No entanto, se a esfera pública política é a categoria central da compreensão habermasiana do procedimento político deliberativo, não o é, entretanto, no seu todo. O conteúdo normativo da esfera pública não se restringe aos arranjos institucionais, depende também das esferas públicas informais. E aqui se vê claramente o papel dos fóruns informais integrantes da esfera pública que já se encontravam presentes na Theorie -. Embora as tomadas de decisão e a filtragem das razões via procedimento formal parlamentar ainda permanecem tarefas da esfera pública formal, são as esferas informais que têm a responsabilidade de identificar e interpretar os problemas sociais. Vêse certa hierarquização que segue dois caminhos de formação da opinião e da vontade: o informal e o institucionalizado. O caminho procedimental da institucionalização da prática da autodeterminação da sociedade civil segue da socialização horizontal para formas verticais de filtragem e organização de temas relevantes. ${ }^{41}$

38 HABERMAS, 1992, Nachwort, p. 625.

39 HABERMAS, 1992, p. 170; 445.

40 HABERMAS, 1992, p. 435.

41 HABERMAS, 1992, Nachwort, p. 679. Neste aspecto, Schmalz-Bruns chama atenção para a necessidade de ampliar os mecanismos institucionalizados de formação da vontade política. Segundo o autor, é preciso conectar os processos de discussão com os de deliberação pública, horizontalizar os processos decisórios, assegurar fóruns deliberativos e lhes conferir poderes efetivos não apenas de discussão, mas também de deliberação (SCHMALZ-BRUNS. Zivile Gesellschaft und Reflexive Demokratie. Forschungsjournal Neue Soziale Bewegungen, 1, p. 18-34, 1994. Sobre isso, ver também: SCHMALZ-BRUNS. Reflexive Demokratie. Nomos Verlag, 1995). 
Até aqui vimos que a concepção de política deliberativa é abordada principalmente sob o aspecto da legitimação. ${ }^{42}$ Vimos também que a noção de "procedimento" da política deliberativa é o cerne do processo democrático habermasiano. Ao ser forjado na esfera pública, o procedimento (e o que dele resulta) fornece a base elementar de medida da legitimidade, e, nesse sentido, também o fundamento ou a justificação normativa. $O$ sentido normativo da esfera pública é conferir força legitimadora ao procedimento da política deliberativa; o sentido normativo reside na força legitimadora do processo de discussão e deliberação que se desenrola no seu interior. $O$ processo democrático da deliberação carrega o fardo da legitimação. ${ }^{43} \mathrm{E}$ daqui brota o "poder comunicativo". O poder comunicativo é o "poder" que resulta do procedimento deliberativo de discussão e deliberação, que toma forma na esfera pública e que geralmente é contraposto à esfera do poder políticoadministrativo. ${ }^{44}$ No entanto, em Faktizität..., a esfera pública não exerce poder, mas influência. Esta é a diferença em relação à ideia de "sitiamento" da Theorie. A figuração na esfera pública não pretende o (nem o conflito gira mais em torno do) sitiamento, mas os diferentes tipos de influência. É essa influência que precisa ser mediada. Para tanto, é fundamental o princípio da soberania popular como procedimento. ${ }^{45}$

42 RESTORFF, Matthias. Die Politische Theorie von Jürgen Habermas. Marburg: Tectum Verlag, 1997. p. 76. 43 HABERMAS, 1992, Nachwort, p. 664.

44 Sobre como a cultura política democrática serve como base elementar de sustentação da democracia deliberativa, ver: PALAZZO, Guido. Die Mitte der Demokratie: Über die Theorie deliberativer Demokratie von Jürgen Habermas. Nomos Verlag, 2000.

45 "Soberania popular" é a ideia-chave para entender a concepção deliberativa de esfera pública. A concepção normativa de esfera pública está apoiada na ideia procedimental de soberania popular. Para Habermas, o procedimento deliberativo toma por base o princípio da soberania popular, capaz de fornecer o substrato de medida da legitimidade. No entanto, para prevenir circunstâncias de um alargamento de oportunidades formais que poderiam emergir de interesses especiais ou grupos específicos, perturbando ou controlando os fluxos de comunicação, Habermas sugere que a soberania popular seja "procedimentalizada". A "soberania popular" é dissolvida em procedimentos capazes de garantir as condições que possibilitam aos processos de comunicação pública tomarem a forma de discurso e serem conduzidos aos foros de deliberação e decisão formalmente instituídos. Nesse sentido, a soberania popular não pode manter-se apenas no nível dos discursos públicos informais. Para gerar poder político, sua influência tem de abranger também as deliberações de instituições democráticas de formação da opinião e da vontade. Nesse sentido, embora fixe o resultado de uma formação discursiva da opinião apenas de modo provisório, a "regra da maioria" constitui, para Habermas, um bom exemplo para o aspecto importante de uma regulação jurídica de processos de deliberação. Todos os membros têm que poder tomar parte nos processos de deliberação e decisão, mesmo que de modos diferentes; mas, por razões técnicas, os procedimentos deliberativos têm que ser conduzidos representativamente. Conduzidos desse modo, os procedimentos deliberativos têm que ser porosos e sensíveis aos estímulos, temas e contribuições, informações e argumentos fornecidos por uma esfera pública pluralista, próxima à base (HABERMAS, 1992, p. 210-225). Sobre a reconstrução do conceito de "soberania popular" e a mudança de compreensão de uma esfera pública representativa (central em Strukturwandel...) para uma esfera pública deliberativa (central em Faktizität...), ver: HABERMAS. Volkssouveranität als Verfahren: Ein Normativer Begriff der Öffentlichkeit. In: Die Moderne - ein unvollendetes Projekt. Philosophischepolitische Aufsätze 1977-1990. Leipzig: Reclam Verlag, p. 180-212, 1988. (ed. ampliada de 1992); tb. em 
A política deliberativa obtém sua força legitimadora da estrutura discursiva de um processo público de formação da opinião e da vontade política, a qual preenche sua função social integradora graças à expectativa da qualidade racional de seus resultados. Para tanto, o nível discursivo das comunicações políticas observáveis pode ser tomado como medida para avaliar a eficácia da razão procedimentalizada. ${ }^{46}$ Por isso, o nível discursivo do debate público constitui a variável mais importante. ${ }^{47}$ Mas, como se mede a qualidade e o nível discursivo das formas de comunicação públicas? Para o autor, a "influência da maioria" fornece aqui uma alternativa e constitui uma grandeza empírica. ${ }^{48}$

\section{Discursos críticos}

Para explicar a concepção de democracia procedimental deliberativa, Habermas serve-se de uma concepção normativa de discurso racional. No entanto, esta concepção não é entendida como um ideal filosófico; ela tem um caráter reconstrutivo: de uma sociologia procedimental reconstrutiva, com o objetivo de elucidar nas práticas políticas elementos incorporados, mesmo que distorcidos, da razão existente. ${ }^{49}$ Com esta proposta deliberativa de democracia, vemos uma opção explícita de Habermas: a descrição do procedimento deliberativo serve como pano de fundo para a proposta de circulação e implantação do poder comunicativo, ancorado num sistema de eclusas. Os fluxos comunicativos podem migrar tanto do centro para a periferia quanto da periferia para o centro, dependendo de quem determina ou controla a orientação dos fluxos de comunicação. Mas, apesar desses dois modos de elaborar temas, questões e problemas, interessa a Habermas o caminho que culmina no tratamento formal de temas novos e politicamente relevantes que emergem do mundo da vida e da esfera privada da sociedade civil, e que

Faktizität und Geltung. 4. ed. 1994, p. 600-631; HABERMAS. Drei normative Modelle der Demokratie. In: Die Einbeziehung des Andere, p. 277-292; BRUNKHORST, H. The Public Sphere and the Contradictions of the Current Epoch. From Representation to Deliberation. In: BOHMAN. And Justice for All. Maastricht, 1994. p. 58-71.

46 Habermas, 1992, p. 414-415; 438.

47 Habermas, 1992, p. 369.

48 Habermas, 1992, p. 437-438. A questão da "influência da maioria" também seria retomada numa outra passagem: Habermas, Apêndice a Faktizität und Geltung, p. 327. No entanto, aqui o autor chama a atenção para uma carência, o reconhecimento de uma fraqueza na sua interpretação da neutralidade do procedimento democrático: o fato de não ter investigado em seus pormenores as tendências que hoje fazem do processo democrático o instrumento de uma dominação das maiorias que trata de excluir minorias fortes (uma "tirania da maioria"); uma hegemonia cultural de uma forma de vida que acaba se afirmando sobre minorias (p. 379). Mas, essa questão fica aqui em aberto e precisa ser melhor examinada.

49 HABERMAS, 1992, p. 349. 
migram da periferia ao centro: "A idéia de democracia repousa, em última instância, no fato de que os processos políticos de formação da vontade, que no esquema aqui delineado tem um status periférico ou intermediário, devem ser decisivos para o desenvolvimento político". ${ }^{50}$

No entanto, os argumentos a favor da concepção deliberativa de esfera pública e de política têm sido alvo de muitas críticas. Muitos teóricos que se ocupam com teorias democráticas têm questionado as assunções básicas da teoria política deliberativa que resulta da obra sobre direito e democracia, apontando vários pontos frágeis: o seu incansável procedimentalismo; o caráter idealista; de que a proposta de uma reforma democrática das instituições não seria tão radical assim; a incapacidade de fornecer princípios substantivos de justiça social; de que, apesar da intencionalidade prática, Habermas não explicita nenhum destinatário em particular (a quem ele se endereça?), que as características ou pressupostos deliberativos se manifestam apenas em formas específicas e restritas; entre outros. ${ }^{51}$

Não podemos acompanhar aqui em sua amplitude a bibliografia crítica sobre esfera pública e democracia deliberativa e, portanto, não vamos reproduzir de modo mais detalhado as discussões e controvérsias sobre o tema - o debate de Habermas com as abordagens filosófico-normativas e sociológico-observadoras, entre liberais, comunitaristas e procedimentalistas,

50 HABERMAS, 1992, p. 432.

51 Sobre as vantagens e desvantagens da deliberação, ver: NOBRE; COELHO. Participação e deliberação, 2004; PETERS, B. Deliberative Öffentlichkeit. In: WINGERT; GÜNTHER, 2001, p. 651; SCHEUERMAN. Between radicalism and resignation: democratic theory in Habermas's 'Between Facts and Norms'. In: DEWS, 1999, p. 153; CHAMBERS, Simone. The Politics of Critical Theory. In: RUSH, Fred. The Cambridge Companion to Critical Theory. Cambridge: Cambridge Univ. Press, 2004. p. 233; BAYNES, K. Deliberative democracy and public reason, 2005. Manuscrito. Além disso, ver as coletâneas editadas por: BÄCHTIGER, Andre et al. Empirical Approaches to Deliberative Democracy. Acta Politica, 40, n. 2-3, 2005; FISHKIN, James. Democracy and Deliberation,Yale, 1991; GUTMANN; THOMPSON. Democracy and Disagreement, 1994; BENHABIB, S. Democracy and Difference, Princeton; BOHMAN, James. Public Deliberation, Complexity, and Democracy, 1996; BOHMAN; REGH. Deliberative Democracy, 1997; ELSTER, Jon. Deliberative Democracy, 1998; ROSENFELD, Michael; ARATO, Andrew. Habermas on Law and Democracy, 1998; DRYZEK, John. Deliberative Democracy and Beyond, 2000; FISHKIN; LASLETT. Debating Deliberative Democracy, 2002; NEIDHARDT, Friedhelm. Öffentlichkeit, öffentliche Meinung, soziale Bewegung, 1994; WINGERT; GÜNTHER. Die Öffentlichkeit der Vernunft und die Vernunft der Öffentlichkeit, 2001; CROSSELY, Nick (2004) After Habermas: new perspectives on the public sphere, Blackwell, 2004; PARKINSON, John. Deliberating in the real world: problems of legitimacy in deliberative democracy, 2006; MACEDO, Stephen. Deliberative politics: essays on democracy and disagreement, 1999; MARKELL, Patchen. Contesting consensus: rereading Habermas on the public sphere. Constellations, 3, p. 377-400, 1997; LÖSCH, B. Deliberative Politik: Moderne Konzeptionen von Öffentlichkeit, Demokratie und politischer Partizipation. Westfälisches Dampfboot, 2005; DAELE, W.; NEIDHARDT, F. (1996) Kommunikation und Entscheidung: Politische Funktionen öffentlicher Meinungsbildung und diskursiver Verfahren. Berlin: Sigma, 1996; NEVES, Marcelo. Do consenso ao dissenso: o estado democrático de direito a partir e além Habermas. In: SOUZA, Democracia hoje: novos desafios para a teoria democrática contemporânea. Brasília: Ed. UnB, 2001. p. 111. 
permanecem incompletas. ${ }^{52}$ Para nossos propósitos, vamos aqui nos limitar apenas a alguns comentários sobre deliberação, especialmente aqueles envolvendo a esfera pública deliberativa.

A introdução do princípio da legitimidade deliberativa no processo democrático significa o reconhecimento, por parte dos atores, de que os motivos introduzidos no procedimento de discussão e deliberação e de que o resultado alcançado deu-se sob os holofotes normativos. No entanto, as dúvidas que surgem são: os procedimentos deliberativos são apenas procedimentos de argumentação racional ou também remetem a considerações racionais substantivas? A ênfase da deliberação é nos elementos normativos e consensuais do modelo deliberativo ou é uma ênfase realista nos interesses e no potencial de conflito neles contido? Os mecanismos procedimentais deliberativos realmente conseguem proteger a formação política da opinião e da vontade das influências? O modelo deliberativo consegue neutralizar e suspender disparidades econômicas, sociais, culturais, cognitivas, entre outras, e promover um resultado satisfatório, de igualdade e justiça? Seu aspecto cognitivo realmente introduz uma gradual abolição destas desigualdades e disparidades, promove igualdade e produz resultados políticos justos? Enfim, trata-se de processos de deliberação ideal ou de deliberação efetiva?

52 Sobre isso, ver: HABERMAS. Anerkennungskämpfe im demokratischen Rechtsstaat. In: TAYLOR et al. Multikulturalism und die Politik der Anerkennung. Fischer Verlag, 1994. p. 147-196; HABERMAS. Politischer Liberalismus. Eine Auseinandersetzung mit John Rawls, 1996, p. 65-127; Inklusion: Einbeziehung oder Erschliessen?: Zum Verhältnis von Nation, Rechtsstaat und Demokratie, p. 154-184, Kampf um Anerkennung im demokratischen Rechtsstaat, p. 237-276, ambos in: Die Einbeziehung des Anderen. Suhrkamp; RAWLS, J. A Theory of Justice. Harvard Univ. Press, 1971; RAWLS. Political Liberalism. Columbia Univ. Press, 1996; RAWLS. Reply to Habermas. The Journal of Philosophy, XCII, n. 3, 1995; TAYLOR, C. et al. Multikulturalism und die Politik der Anerkennung. Fischer, p. 147-196, 1994; DWORKIN, R. Law's empire, Harvard Univ. Press, 1986; DWORKIN, R. Fundations of Liberal Equality. Cambridge, 1990; DWORKIN. A Matter of Principle, Harvard Univ. Press, 2000; LUHMAN. Beobachtungen der Moderne. Westdeutscher Verlag, 1992; LUHMANN, N. Das Recht der Gesellschaft. Suhrkamp, 1995; FORST, Rainer. Kontexte der Gerechtigkeit: Politische Philosophie jenseits von Liberalismus und Kommunitarismus. 2. ed. Suhrkamp, 2004; MCCARTHY. Kantian Constructivism and Reconstructivism: Rawls and Habermas in Dialogue. Ethichs, 105, p. 44-63, 1994; MCCARTHY. Practical discourse: on the relation of morality to politics. In: Craig CALHOUN. Habermas and the Public Sphere, p. 51-72, 1992.; BAYNES, K. Practical reason, the 'spaces of reasons', and 'public reason. In: BOHMAN; REGH. Pluralism and the pragmatic turn. MIT Press, 2001; KUKATHAS; PETIT. Rawls: A Theory of Justice and its Critics. Polity, 1990; VITA, Alvaro de. A Justiça Igualitária e seus Críticos. Ed. Unesp, 2000; BRUNKHORST. Rawls and Habermas. In: BAYNES; SCHOMBERG. Discourse and Democracy, p. 153161, 2002; DRYZEK, J. Deliberative Democracy and Beyond. Oxford University Press, 2000; TALISSE, R. Democracy after liberalism: pragmatism and deliberative politics. New York Univ. Press, 2005; E. CHARNEY, E. Political liberalism, deliberative democracy, and the public sphere. American Political Science Review 92, 1998; GERHARDS, Jürgen. Diskursive versus liberale Öffentlichkeit: Eine empirische Auseindersetzung mit Jürgen Habermas. Kölner Zeitschrift für Sozialforschung und Sozialpsichologie, 49, p. 1-34, 1997. E, ainda, as coletâneas organizadas por: FELIPE, Sônia (Org.). Justiça como eqüidade: fundamentação e interlocuções polêmicas. Florianópolis: Insular, 1998; DUTRA, Delamar V.; PINZANI, Alessandro. Habermas em Discussão. Ed. UFSC, 2005. 
As expectativas políticas de uma esfera pública normativa estão depositadas na força crítica do modelo deliberativo de comunicação pública e de circulação do poder. Mas, embora este modo de comunicação pública carregue fortes expectativas normativas de entendimento e de consenso, as limitações para a realização de tais condições de comunicação são bem conhecidas. Há exemplos, observáveis na bibliografia, de pressupostos limitadores, internos e externos. Dissensos, formas não-discursivas de comunicação pública, desigualdades, assimetrias, estratificação social, estruturas de poder, fragmentação do universo simbólico, diversidade de modos de vida cultural, pluralismo das visões de mundo, convicções religiosas, temas controversos, os efeitos de certas formas de comunicação estratégica, ou interesses específicos relacionados a classes, grupos, comunidades étnicas, comunidades religiosas, ou sub-culturas com orientações específicas ou alternativas.

Para autores como John Dryzek, James Bohman e Mark Warren, o modelo de democracia deliberativa que se assenta no princípio procedimental de soberania popular está muito concentrado, ou direcionado por demais, na arquitetônica institucional. Em contrapartida, tais autores têm em comum a tentativa de desenvolver modelos de democracia que se ocupam com um conceito pós-habermasiano de soberania popular. Um conceito de democracia que, embora articulado na sociedade civil e na esfera pública, seja, no entanto, mais amplo e mais descentrado dos liames institucionais. ${ }^{53}$

Para Simone Chambers, embora Habermas seja um radical democrata procedimental, não é, no entanto, um radical democrata social, e, por isso, é incapaz de fornecer princípios substantivos de justiça social. ${ }^{54}$ Para Kenneth Baynes, o modelo deliberativo não pode ignorar completamente princípios substantivos de justiça. ${ }^{55}$ Parece-nos que é nesse sentido que emergem as objeções mais contundentes à concepção deliberativa de esfera pública e de política habermasiana.

Para William Scheuerman, Habermas teria falhado em não encarar de modo suficiente o potencial radical da democracia deliberativa (democracia radical). Por exemplo, desigualdades sociais seriam barreiras para que os membros de uma comunidade política sejam aptos a participar da geração da legitimidade do poder. As condições materiais das sociedades globalizadas,

53 DRYZEK, John. Deliberative Democracy and Beyond. Oxford Univ. Press, 2000; BOHMAN, J. Pluralismus, Kulturspezifizität und kosmopolitische Öffentlichkeit im Zeichen der Globalisierung. In: Deutsche Zeitschrift für Philosophie, p. 927-941, 1997; WARREN, Mark. What can Democratic Participation mean Today? Political Theory 30, p. 677-702, 2002.

54 CHAMBERS, 1996, p. 233.

55 BAYNES, K. Deliberative democracy and public reason, p. 35. 
com suas dinâmicas complexas, suas condições internas (poder, consumismo, mídia, por exemplo) acabam privando a autêntica participação democrática. Segundo o autor, interações exigem um certo nível, têm que se dar sob certas condições, sem coações externas (econômicas ou de poder, por exemplo). Por isso, tornam-se necessários certos níveis de igualdade e respeito entre os participantes da comunicação pública; mecanismos capazes de evitar as influências das desiguais condições socioeconômicas. Para o autor, o modelo deliberativo não consegue fornecer condições estruturais de comunicação pública isentas de certos tipos de influência que desvirtuam ou afetam a qualidade e o resultado do processo deliberativo. O modelo deliberativo não consegue cumprir todas as exigências normativas da publicidade, racionalidade e igualdade nos mais diferentes níveis e arenas da esfera pública. ${ }^{56}$

A concepção deliberativa da democracia considera a participação dos cidadãos nas deliberações e nas tomadas de decisão o elemento central da compreensão do processo democrático. Nesse sentido, focaliza os elementos formais e normativos, como a exigência do aumento da participação dos cidadãos nos processos de deliberação e decisão e o fomento de uma cultura política democrática. O procedimento da deliberação não é apenas uma etapa de discussão que antecede a tomada de decisão. Mais do que isso, ela tem o objetivo de justificar as decisões a partir de razões que todos poderiam aceitar. Esse é o procedimento deliberativo da razão pública: fornecer um espectro de razões que poderiam ser aceitas por todos os possíveis atingidos, ainda que nem todos compartilhem com o tema ou assunto em questão, ou com a mesma filosofia de vida. Segundo Marcos Nobre:

O procedimento, para Habermas, é "formal", mas não em oposição a conteúdos determinados, de que ele seria a abstração, ou em relação aos quais ele seria "vazio", mas o processo capaz de permitir o surgimento do maior número possível de vozes, de alternativas de ação e de formas de vida, garantindo seu direito de expressão e de participação. Ele é formal também no sentido de que o processo de deliberação política não pode ser orientado por nenhuma forma de vida determinada, por nenhum modelo concreto do que deva ser a sociedade ou os cidadãos que vivem em um Estado Democrático de Direito. ${ }^{57}$

56 Ver: SCHEUERMAN, W. E. Between Radicalism and Resignation: Democratic Theory in Habermas's 'Between Facts and Norms. In: DEWS, 1999; FRASER, Nancy. Rethinking the Public Sphere: a Contribution to the Critique of the Actually Existing Democracy. In: CALHOUN, 1992.

57 NOBRE. Introdução. In: NOBRE; TERRA, 2008, p. 18. 
Como podemos ver, a deliberação é um procedimento que indica quem deve participar e como, mas não tem nada a dizer sobre o preenchimento dos conteúdos normativos. Por esse modo, o princípio formal da deliberação democrática não pode ser confundido ou reduzido a outros bens, também valiosos, como "justiça social", "Estado de direito", "direitos sociais" e "direitos culturais", mais próximos das teorias explicativas da democracia, fundados nos interesses e nas preferências dos indivíduos (preferências e interesses substantivos: ou sociais, ou materiais, ou culturais, ou ainda outros). Os procedimentos deliberativos escapam das restrições de uma única dimensão da razão prática, seja moral, ética ou pragmática. ${ }^{58}$ Nesse sentido, os aspectos procedimentais do uso público da razão, ao confiarem mais no procedimento deliberativo de uma formação da opinião e da vontade, podem deixar questões em aberto.

A concepção procedimental de democracia carrega no seu bojo uma "tensão" entre facticidade e validade. Esta relação entre ambas constitui-se numa constante tensão encontrada nos pressupostos pragmáticos contrafactuais que, mesmo carregado de pressupostos idealizadores, têm que ser admitidos factualmente por todos os participantes quando estes desejam participar de uma argumentação discursiva a fim de justificar ou negar pretensões de validade. Os "pressupostos idealizadores" - de inclusão, acesso universal, direitos comunicativos iguais, participação sob igualdade de direitos, igualdade de chances para todas as contribuições, ausência de coações apenas têm o caráter de garantir formalmente uma pressuposição fática para gozar chances iguais. ${ }^{59}$ Para Habermas, esta tensão é desconsiderada pelas teorias normativistas (que correm o risco de perder o contato com a realidade social) e as teorias objetivistas (que correm o risco de serem incapazes de focalizar normas) ${ }^{60}$

A tensão, o conflito, a disputa política que se desenrola nas esferas públicas são inerentes ao próprio procedimento, um "jogo" no qual já sempre estamos envolvidos como participantes quando pretendemos discutir, justificar ou negar pretensões de validade. Este conflito se alimenta de um jogo que envolve uma esfera pública ancorada na sociedade civil e a formação institucionalizada no complexo parlamentar, um jogo que envolve a formação da vontade formal e institucionalizada e a formação informal da opinião. ${ }^{61} \mathrm{~A}$

58 WERLE, D. Democracia deliberativa e os limites da razão pública. In: NOBRE; COELHO, 2004, p. 148-149. 59 HABERMAS, Apêndice a Faktizität und Geltung, p. 340-341.

60 HABERMAS, 1992, p. 21

61 HABERMAS, 1992, p. 374. 
tensão gira em torno dos fluxos comunicativos, ou melhor, de quem determina o sentido dos fluxos de comunicação e que elaboram pretensões normativas na sociedade e no sistema político. Uma tensão entre o poder comunicativo gerado na base social do mundo da vida e o poder administrativo gerado no sistema político.

A própria esfera pública é entendida, por característica, como um espaço irrestrito de comunicação pública. Nada pode ser estabelecido ou restringido de antemão. Qualquer assunto ou questão problematizável pode ser tematizado publicamente, no qual os contornos da esfera pública vão sendo forjados nos processos de escolha, circulação e proposta de temas, e os conteúdos normativos vão sendo preenchidos dependendo de quem controla ou orienta os fluxos de comunicação que figuram na esfera pública. ${ }^{62}$ A qualidade da deliberação que se configura na esfera pública depende de um procedimento no qual os cidadãos disputam interpretações de contribuições por tanto tempo até que cada um esteja convencido de que foram empregados os melhores argumentos. Este processo é garantido pelo caráter procedimental da deliberação. No entanto, o resultado desse processo permanece "provisório". Isso significa: caso sejam encontrados argumentos melhores, o procedimento de crítica pública pode ser reaberto. Esse é o caráter reflexivo (e crítico) da esfera pública deliberativa. Segundo Nobre:

Se a deliberação e a participação devem encontrar seu lugar no Estado Democrático
de Direito, será necessário aceitar um jogo entre, de um lado, os espaços públicos
autônomos e as novas formas de institucionalidade que projetam, e, de outro,
macroestruturas definidoras do regime democrático, que serão cada vez mais testadas
em seus limites e suas configurações presentes. Entretanto [acentua Nobre], não se
trata de um "livre jogo" entre os dois pólos, mas uma disputa política que só mostrará
avanços emancipatórios se for capaz de afastar, a cada vez, em cada conflito concreto,
o jugo determinante do dinheiro e poder administrativo.

Esta compreensão falível do paradigma procedimental tem implicações sobre a compreensão da justiça e o sentido da igualdade. Em primeiro lugar, uma esfera pública, ou de modo mais abrangente, um mundo da vida racionalizado, exige uma base social material e simbólica por meio da superação das barreiras criadas pela estratificação social e pela exploração sistemática. E aqui nos parece claro que a ênfase da teoria democrática habermasiana gira em torno

62 PETERS, B. “Der Sinn der Öffentlichkeit”, p. 62.

63 NOBRE. Participação e deliberação na teoria democrática: uma introdução. In: NOBRE; COELHO, 2004, p. 37. 
não apenas da democracia política (os pressupostos formais, como direitos de cidadania, participação, e outros), mas também reivindica democracia social. ${ }^{64}$

Em segundo lugar, a intenção de Habermas não é fornecer um princípio "substantivo" de justiça, como já vimos. Pelo contrário, os esforços empregados em Faktizität und Geltung visam justamente abolir princípios substantivos, em favor de "procedimentos deliberativos", e mostrar a correlação equilibrada entre a compreensão da autonomia pública e autonomia privada. Para Habermas, "essa concatenação interna (e recíproca) entre autonomia privada e pública, quando a entendemos corretamente, constitui o âmago normativo do paradigma procedimental". ${ }^{65}$

Em terceiro lugar, esta crítica habermasiana visa explicitar as debilidades normativas dos modelos liberal e republicano, que, por exemplo, fixam de antemão a escolha sobre o sentido da igualdade jurídica; ou fixam de antemão quais assuntos são privados e quais são públicos. Com o paradigma procedimental, a determinação do sentido da igualdade é lançada no campo político de comunicação pública. O conteúdo da igualdade jurídica deve ser considerado objeto de uma disputa política. Um conflito no qual o sentido da igualdade é decidido num processo de comunicação pública, conduzido pelos próprios participantes e possíveis afetados por meio do exercício público de formação democrática da opinião e da vontade. O modelo deliberativo considera os próprios concernidos como responsáveis pela definição dos critérios de igualdade a serem aplicadas ao sistema de direitos.

Com isso, a fundamentação de igualdades materiais é incorporada na teoria democrática como uma disputa política em torno do que precisa ser reconhecido. Uma luta pelo reconhecimento jurídico de necessidades e exigências normativas peculiares em relação ao conjunto de toda a comunidade jurídica, na qual os grupos interessados procuram apresentar aos demais as experiências particulares de exclusão social, discriminação e carências em vista do convencimento sobre a necessidade de um tratamento jurídico formalmente diferenciado. Segundo o princípio amplo da igualdade do conteúdo do direito, aquilo que é igual sob aspectos relevantes deve ser tratado de modo igual, e aquilo que é diferente deve ser tratado de modo diferente. ${ }^{66}$

Esta perspectiva procedimental abre a possibilidade de avaliação motivada pela própria experiência sofrida com a não realização de direitos, das 
alternativas existentes em relação à permanência no paradigma social ou um retorno ao paradigma liberal. Nesse sentido, Habermas encontra a emergência do paradigma procedimental já enraizada em algumas vertentes da prática jurídica contemporânea, que se vê encurralada entre a crítica ao modelo social e a rejeição do retorno ao modelo liberal. ${ }^{67}$ No entanto, é em certos desenvolvimentos de movimentos feministas de esquerda norte-americanos que Habermas encontra a melhor expressão das exigências normativas, da necessidade de uma orientação procedimentalista da prática jurídica contemporânea: o movimento feminista, ao ter experimentado as limitações específicas de ambos os paradigmas anteriores, estaria agora em condições de negar a cegueira em relação às desigualdades factuais do modelo paternalista social. Nesse caso, as diferentes interpretações sobre a identidade dos sexos e suas relações mútuas têm de se submeter a discussões públicas constantes, no qual as próprias concernidas podem reformular o tema ou assunto em questão a ser reconhecido, e elas mesmas decidirem quais as necessidades que precisam ser corrigidas pelo medium do direito. ${ }^{68}$

As reformulações da década de 90 tomadas como ponto de partida e como fio condutor da investigação habermasiana são um passo importante na readequação da categoria de esfera pública às novas questões e problemáticas que vão sendo incorporadas na discussão sobre o tema da esfera pública, suas características, suas funções, seus portadores, suas articulações com outras esferas e instâncias mediadoras. A reformulação da categoria de esfera pública no "prefácio" de 1990 a Strukturwandel der Öffentlichkeit, e em Faktizität und Geltung (com uma ênfase maior sobre o institucional, e a reformulação da noção de sistema político, mais aberto e mais poroso), é uma tentativa de melhor contextualizar e compreender as novas articulações mediadoras que emergiram entre as esferas do mundo da vida e da sociedade civil, e as esferas institucionais do sistema político e administrativo. Trata-se de reavaliar os

67 HABERMAS, 1992, p. 494-499.

68 HABERMAS, 1992, p. 504-515. Sobre o debate feminista, ver: YOUNG, Iris M. Justice and the Politics of Difference. Princeton, 1990; YOUNG. Inclusion and Democracy. Cambridge Univ. Press, 2001; FRASER, N. Justice Interruptus: Critical Reflections on the Postsocialist Condition. Routledge, 1997; S. BENHABIB, S. (Ed.) Democracy and Difference. Princeton Univ. Press, 1996, e BENHABIB Claims of Culture. Princeton Univ. Press, 2002. Além disso, ver: PATEMAN, Carole. Participation and democratic theory. Cambridge Univ. Press, 1970; PHILIPS, Anne. Feminism and Equality. Oxford: New York Univ. Press, 1987; RHODE, L. D. Justice and Gender. Cambridge, 1989; LANDES, Joan. Jürgen Habermas, the structural transformation of the public sphere: a feminist inquiry. Praxis International 12, p. 106-127, 1992. 
mecanismos de participação democrática, os elementos argumentativos e o peso que exercem nos processos de formação da opinião e da vontade e nos novos arranjos institucionais. Nesse sentido, Habermas pode não ter explicitado nenhum destinatário em particular, mas as reformulações da esfera pública da década de 90 resgatam a importância e o papel da sociedade civil, outorgando-lhe o direito à participação e argumentação, ao impacto crescente da reflexividade e à democracia formal. No entanto, é a partir deste cenário teórico da nova compreensão da circulação do poder político, da concepção deliberativa de esfera pública e de política, que também emergem as objeções críticas mais contundentes sobre as implicações práticas, possibilidades de efetividade e influência na institucionalização de reivindicações que emergem das mais diversas organizações da sociedade civil, e que sejam capazes de promover mudanças no sistema político. Vejam-se as controvérsias sobre as possibilidades de uma esfera pública pós-nacional.

Nos "Estudos Preliminares e Complementos" e no "Posfácio" à quarta edição de Faktizität und Geltung, ${ }^{69}$ na entrevista "Faktizität und Geltung. Ein Gespräch über Fragen der politischen Theorie", ${ }^{70}$ e no "Apêndice a 'Faktizität und Geltung", ${ }^{71}$ Habermas retoma e busca elucidar as controvérsias acerca da esfera pública e da política deliberativa, a relação entre esferas informais do mundo da vida e as esferas formais do sistema político institucionalizado, e o modo como no seu bojo se articula essa mediação. No entanto, parece-nos que esta tentativa de melhor esclarecer a articulação entre a autocompreensão normativa do estado de direito e a facticidade dos processos políticos já se movimenta sob um modificado pano de fundo teórico da esfera pública. Depois da obra Faktizität und Geltung, as discussões habermasianas sobre as possibilidades práticas do modelo deliberativo de esfera pública foram aos poucos sendo aplicadas para o campo político pós-nacional. Especialmente a partir de Die Einbeziehung des Anderen (1996), são tematizadas novas questões e problemas envolvendo a esfera pública, mas já pensadas e empregadas num contexto mais amplo e vinculadas a temas como multiculturalismo, tolerância, reconhecimento, redistribuição, fundamentalismo, secularização, entre outros. ${ }^{72}$ Mas, como entender esse deslocamento? Seria uma nova

69 HABERMAS. Faktizität und Geltung, 4. ed., 1994, "Vorstudien und Ergänzungen", e "Nachwort”.

70 HABERMAS. Faktizität und Geltung. Ein Gespräch über Fragen der politischen Theorie. In: HABERMAS. Die Normalität einer Berliner Republik, 1995, p. 133.

71 HABERMAS, Apêndice a Faktizität und Geltung, 1996, Die Einbeziehung des Anderen, p. 309.

72 HABERMAS. Die Einbeziehung des Anderen, 1996; HABERMAS (1998) Die postnationale Konstellation, 1998; HABERMAS. Zeit der Übergange, 2001; HABERMAS. Der Gespaltene Westen, 2004; HABERMAS. Zwischen Naturalismus und Religion, 2005; HABERMAS. A political constitution for pluralist world society?, 2005, Manuscrito. Além disso, ver: HABERMAS. Die Zukunft der Menschlichen Natur, 2001; HABERMAS. 
reformulação? Seria uma transferência? Ou seria um outro campo de aplicação? Ou como entendê-lo? Parece-nos que a categoria de esfera pública e questões como a relação entre autonomia pública e privada, entre soberania popular e direitos humanos, entre democracia e Estado de direito, são pensadas num contexto aplicativo modificado, o âmbito internacional (de uma esfera pública pós-nacional e de uma teoria política universalista). Mas, isso precisa ser melhor investigado.

As recentes transformações nos panoramas social, político, econômico, cultural e religioso, refletem uma nova dinâmica envolvendo estados nacionais que se juntam em comunidades regionais e supranacionais, de sociedades pluralistas nas quais a intolerância multicultural se agudiza, e na qual os cidadãos estão sendo empurrados e incorporados involuntariamente numa sociedade mundial, e classificados em centro e periferia. A expansão do debate sobre a esfera pública para um âmbito global (Weltöffentlichkeit) significa que o contexto teórico específico que até aqui serviu de base para a discussão e descrição das possibilidades de uma esfera pública (cultura política comum engenhada no âmbito territorial nacional, Estado-nação ou a autoridade do Estado como endereço político do público, soberania popular, estado democrático de direito, constituição, direito), já não seria mais suficiente para compreender a nova dinâmica engendrada pelo processo de globalização do capital e da política em termos internacionais, ou as repercussões em escala mundial como a queda do socialismo de estado nos países do leste europeu que engendraram novas experiências de democratização, o movimento feminista crescente em termos mundiais, e os movimentos de democratização na China $^{73}$ e na África. ${ }^{74} \mathrm{~A}$ reorientação habermasiana para um âmbito temático pós-nacional visa discutir as possibilidades e formas de um projeto constitucional de um estado democrático e de democracia deliberativa que envolvam a esfera pública no nível global. Habermas parte do princípio de que os estados nacionais não conseguem mais dar conta dos problemas de legitimação da política, (ou dos efeitos colaterais de outras esferas de ação, como a economia), decorrentes da movimentação transnacional, e que acaba afetando, de uma forma ou de outra, os mecanismos de legitimação institucionalizados nos estados nacionais. Nesta perspectiva, a estrutura

Glauben und Wissen, 2001; HABERMAS. Zeitdiagnosen: Zwölf Essays, 2003; HABERMAS. Dialektik der Säkularisierung: Über Vernunft und Religion, 2005; HABERMAS; DERRIDA. Philosophy in a time of terror: dialogues with Jürgen Habermas and Jacques Derrida. University of Chicago Press, 2003.

73 Peter Hohendahl (2000) Öffentlichkeit - Geschichte eines kritischen Begriffs, Metzler Verlag, p.114.

74 Ukoro Theophilus Igwe (2004) Communicative rationality and deliberative democracy of Jürgen Habermas: toward consolidatiom of democracy in Africa. Münster: Lit Verlag. 
teórica de base da esfera pública formulada em Faktizität und Geltung já necessitaria de uma outra reformulação: ser compreendida e aplicada nos contextos europeu e global. Uma esfera pública deliberativa pós-nacional, de dimensões ampliadas, seria uma arena mais adequada para a tematização de problemas relevantes comuns, e para fornecer uma melhor solução aos atuais problemas de legitimação enfrentados pelas instâncias normativas legais internacionais institucionalizadas. A tese geral de Habermas é a compreensão de uma esfera pública global como sendo uma extensão das características de uma cultura política nacional, no entanto, apenas aplicadas para os níveis europeu e mundial, respectivamente.

Desde a metade dos anos 90, Habermas e os teóricos da deliberação têm se ocupado com as possibilidades e dificuldades de procedimentos deliberativos nas arenas internacionais da esfera pública e da política. Por um lado, estudos indicam que a categoria de esfera pública deliberativa provê uma perspectiva analítica apropriada para analisar procedimentos deliberativos em pequenos grupos; que questões de participação e deliberação funcionam melhor em interações locais, conferindo modos mais efetivos de participação democrática. ${ }^{75}$ Por outro lado, estudos indicam que há evidências de que a concepção de esfera pública deliberativa provê uma perspectiva analítica apropriada para analisar também procedimentos deliberativos nas esferas nacionais e internacionais - embora nesse nível haja também falhas evidentes nos procedimentos deliberativos de uma esfera pública política dominada por uma comunicação pública mediada pelos meios de comunicação de massa e estruturas de poder, pois as dinâmicas de comunicação de massa são dirigidas pelo poder seletivo da mídia e pelo uso estratégico do poder social e político para influenciar a triagem e o estabelecer da agenda dos assuntos públicos. ${ }^{76}$

75 Sobre isso, ver os artigos em Acta Politica, 40, n. 3, 2005, Parte III ("Deliberation among Citizens"): CONOVER; SEARING. Studing 'everiday political talk' in the deliberative system, p. 269-283; FISHKIN; LUSKIN. Experimentig with democratic ideal: deliberative pooling and public opinion, p. 284-298; KRIESI, Argument-based strategies in direct-democratic votes: the Swiss experience, p. 299-316; KIES; JANSEN. Online forums and deliberative democracy: hypotheses, variables and methodologies, p. $317-335$. Além disso, ver: KRIESI, H. Akteure, Medien, Publikum. Die Herausforderung direkter Demokratie durch Transformation der Öffentlichkeit. In: NEIDHARDT. Öffentlichkeit, Öffentliche Meinung, Soziale Bewegungen, 1994, p. 234-259; HAJER, M.; WAGENAAR, H. Deliberative Policy Analysis. Cambridge University Press, 2003; FISCHER, Frank. Reframing public policy: discursive politics and deliberative practices. Oxford Univ.Press, 2003; OTTERSBACH, M. Außerparlamentarische Demokratie: Neue Bürgerbewegungen als Herausforderung an die Zivilgesellschaft. Campus Verlag, 2004; BABER, W.; BARTLETT, R. Deliberative environmental politics: democracy and ecological rationality, Cambridge MIT Press, 2005; ROLOFF, J. Sozialer Wandel durch deliberative Prozesse. Metropolis Verlag, 2006.

76 Sobre isso, ver os artigos em Acta Politica, 40, n. 2, 2005, Parte I ("A systemic vision of deliberation"): Goodin, Sequencing deliberative moments, p. 182-196; DRYZEK. Handle with care: the deadly hermeneutics of deliberative instrumentation, p. 197-211; ROSEMBERG, The empirical study of deliberative democracy: setting a research agenda, p. 212-224; Os artigos da Parte II ("Deliberation in formal arenas"): 
Sendo assim, como os teóricos lidam com procedimentos deliberativos que se estendem para além das interações simples e se configuram num contexto de aplicação mais amplo, mais complexo e mais pluralista? Como conciliar a necessidade de participação e de procedimentos deliberativos em contextos de interação social que exibem um incremento impressionante no volume da comunicação política, e que precisa lidar com dimensões tão ampliadas? Como são pensadas a participação e a deliberação democrática no nível global? Como é pensada a interconexão entre as esferas do mundo da vida situadas localmente com processos de comunicação pública no nível global? Como poderia dar-se essa conexão? Ao tematizar a Weltöffentlichkeit, Habermas ainda se move na chave teórica da teoria dual da sociedade como sistema e mundo da vida? Embora Habermas afirme que a deliberação na esfera pública, como um mecanismo de solução de problemas e resolução de conflitos, ainda está fracamente institucionalizada nesse nível, esta é uma outra questão que permanece aqui em aberto e precisa ser melhor investigada. ${ }^{77}$

BÄCHTIGER, A. et al. The deliberative dimensions of legislatures p. 225-238; HOLZINGER. Context or conflict types: which determines the selection of communication mode, p. 239-254. Sobre "Deliberation at the International Level", ver: Acta Política, 40, n.3, Parte IV: PORTA, D. Deliberation n movement: why and who to study deliberative democracy and social movements, p. 336-350; ULBERT; RISSE. Deliberative changing of discourse: what does making arguing effective?, p. 351-367; NANZ; STEFFEK. Assessing the democratic quality of deliberation in international governance: criteria and research strategies, p. 368-383. Além disso, ver: WILLIAM, N. The Institutions of Deliberative Democracy. Social Philosophy \& Policy, 17, p. 181-202; GERHARDS et al. Shaping abortion discourse: democracy and the public sphere in Germany and United States, 2002. E alguns artigos in: NOBRE; COELHO. Participação e deliberação, entre eles: FUNG, Archong. Receitas para esferas públicas: oito desenhos institucionais e suas conseqüências, p. 173-209, VITALE, Denise. Democracia direta e poder local: a experiência brasileira do orçamento participativo, $p$. 239-254; MATOS, Paulo. Regulação econômica e social e participação pública no Brasil, p. 313-342, e LAVALLE, Adrián et al. Lugares e atores da democracia: arranjos institucionais participativos e sociedade civil em São Paulo, p. 343-367.

77 HABERMAS. Concluding Comments on Empirical Approaches to Deliberative Politics. Acta Política. International Journal of Political Science, v. 40, n. 3, p. 386. E este é o ponto de partida da maioria dos estudos, teóricos e empíricos, sobre os procedimentos deliberativos na esfera internacional da política. Ver também: BRUNKHORST, H. Jenseits von Zentrum und Peripherie. Zur Verfassung der fragmentierten Weltgesellschaft. Rainer Hampp Verlag, 2005; BRUNKHORST. Völkerrechtspolitik. Recht, Staat und Internationale Gemeinschaft im Blick auf Kelsen. Hamburg: Liszt Verlag, 2006; BRUNKHORST. Europa im Kontext der Weltgesellschaft, 2006, Manuscrito; BRUNKHORST. Legitimationskrise in der Weltgesellschaft, 2006, Manuscrito; BOHMAN, J. Pluralismus, Kulturspezifizität und kosmopolitische Öffentlichkeit im Zeichen der Globalisierung. Deutsche Zeitschrift für Philosophie 45.6, p. 927-941, 1997; HELD, D. Democracy an the global order: From the modern state to cosmopolitam governance, 1995; EDER, Klaus. Zur Transformation nationalstaatlicher Öffentlichkeit in Europa. Berliner Journal für Soziologie, n. 2, p. 167184, 2000; FRASER, N. Transnationalizing the public sphere. New York, 2002, Manuscrito; KRAUS, Peter. Democracy, communication and language in Europe's transnational political space. Wissenschaftzentrum Berlin, 2005; HÖFFE, Ottfried (1999) Demokratie im Zeitalter der Globalisierung. München: Beck, 2005; NANZ, Peter. European Community without a demos? Rethinking conceptions of the public sphere. Berlin: Wissenschaftszentrum, 2005; DI FÁBIO, Udo Der Verfassungstaat in der Weltgeselschaft. Tübingen: Mohr, 2001; LESCANO, Andreas Fischer. Globalverfassung. Die Geltungsbegründung der Menschenrechte. Weilerswist: Velbrück Wissenschaft, 2005; LUTZ-BACHMAN, Mathias; BOHMAN, James. Weltstaat oder Staatwelt? Für und wider die Idee einer Weltrepublik, 2002; MÜLLER, Friedrich. Demokratie zwischen Staatsrecht und Weltrecht: Nationale, staatlose und globale Formen menschenrechtsgestützer 


\section{Referências}

AVRITZER, L. Democracy and the Public Space in Latin America. Princeton: Princeton Univ. Press, 2002.

BENHABIB, Seyla. Models of Public Space: Hannah Arendt, the Liberal Tradition, and Jürgen Habermas. In: CALHOUN, Craig. Habermas and the Public Sphere. Cambridge, MA: MIT Press, 1992. p. 73-98.

BOHMAN, J. Expanding Dialogue: the Internet, the Public Sphere and Prospects for Transnational Democracy. In: CROSSELY, N. After Habermas: new perspectives on the public sphere. Oxford, UK: Blackwell, 2004. p. 131-155.

BOHMAN, J. Pluralismus, Kulturspezifizität und kosmopolitische Öffentlichkeit im Zeichen der Globalisierung. Deutsche Zeitschrift fürPhilosophie, 45.6, p. 927-941, 1997.

BOHMAn, J. Public Deliberation, Complexity, and Democracy. Cambridge, MA: MIT Press, 1996.

BOHMAN, J.; REHG, William. Deliberative Democracy. Essays on Reason and Politics. Cambridge, MA: MIT Press, 1997.

BRUNKHORST, Hauke. Demokratischer Experimentalismus: Politik in der komplexen Gesellschaft. Frankfurt am Main: Suhrkamp, 1998.

BRUNKHORST, Hauke. Europa im Kontext derWeltgesellschaft. 2006. Manuscrito. BRUNKHORST, Hauke. Globale Solidarität: Inklusionsprobleme der modernen Gesellschaft. In: WINGERT, Lutz; GÜNTHER, Klaus. Die Öffentlichkeit der Vernunft und die Vernunft der Öffentlichkeit. Frankfurt am Main: Suhrkamp, 2001. p. 605-626. BRUNKHORST, Hauke. Globalisierung und Demokratie. Wirtschaft, Recht, Medien. Frankfurt am Main: Suhrkamp, 2000.

BRUNKHORST, Hauke. Globalizing Democracy without a State: Weak Public, Strong Public, Global Constitutionalism. Millenium - Journal of International Studies, n. 31, p. 675-690, 2002.

BRUNKHORST, Hauke. Habermas. Reclam Verlag, 2006.

BRUNKHORST, Hauke. Internationale Verrechtlichung und Demokratie. Frankfurt am Main: Goethe-Universität, 2006.

BRUNKHORST, Hauke. Jenseits von Zentrum und Peripherie: Zur Verfassung derfragmentierten Weltgesellschaft. [S.1.]: Rainer Hampp Verlag, 2005.

BRUNKHORST, Hauke. Legitimationskrise in der Weltgesellschaft. 2006. Manuscrito.

Globalisierung. Elemente einer Verfassungstheorie VIII. Berlin: Duncker \& Humblot, 2003; STICHWEH, R. Die Weltgesellschaft. Suhrkamp, 2000; TEUBNER, Günther. Globale Zivilverfassungen: Alternativen zu Staatszentrierten Verfassungstheorie. Zeitschrift für ausländisches Recht und Völkerrecht. Bd. 63, n.1, 2003; GIESEN, Klaus-Gerd. Habermas, a segunda Modernidade e a sociedade civil internacional. Novos Estudos Cebrap, 60, p. 87-96, 2001; FARIAS. Globalização e estado cosmopolita: antinomias de Jürgen Habermas, 2001; HERBORT, B.; NIESEN, P. Anarchie der kommunikativen Freiheit: Jürgen Habermas und die Internationalen Politik, 2007. 
BRUNKHORST, Hauke. Peripherie und Zentrum in der Weltgesellschaft. Rainer Hampp Verlag, 2004.

BRUNKHORST, Hauke. Recht auf Menschenrecht. Menschenrechte, Demokratie und Internationale Politik. Frankfurt am Main: Suhrkamp, 1999.

BRUNKHORST, Hauke. Solidarität. Von der Bürgerfreundschaft zur globalen Rechtsgenossenschaft. Frankfurt am Main: Suhrkamp, 2002.

BURKE, Peter. A esfera pública 40 anos depois. Folha de S. Paulo, São Paulo, 24 mar. 2002, "Caderno Mais!".

CALHOUN, Craig. Habermas and the Public Sphere. Cambridge, MA: MIT Press, 1992.

CHAMBERS, S. Reasonable Democracy: Jürgen Habermas and the Politics of Discourse. Ithaca, N.Y.: Cornell University Press, 1996.

COHEN, J. Civil Society and Political Theory. Cambridge, MA: MIT Press, 1992.

COHEN, J.; ARATO, A. Politics and the Reconstruction of the Concept of Civil Society. In: HONNETH, Axel et al. Zwischenbetrachtungen: Im Prozeß der Aufklärung. Frankfurt am Main: Suhrkamp, 1989. p. 482-503.

COSTA, S. As cores de Ercília: esfera pública, democracia, configurações pósnacionais. Belo Horizonte: Ed. UFMG, 2002.

COSTA, S. Der Kampf um Öffentlichkeit: Begriffe, Akteure, politische Dynamiken. Jahrbuch Lateinamerika, Hamburg, n. 28, p. 13-31, 2004.

COSTA, S. Dimensionen der Demokratisierung. Öffentlichkeit, Zivilgesellschaft und lokale Partizipation in Brasilien. Frankfurt am Main: Vervuert, 1997.

COSTA, S. Esfera pública, redescoberta da sociedade civil e movimentos sociais no Brasil: uma abordagem tentativa. Novos EstudosCebrap, São Paulo, 38, p. 38-52, 1994.

CROSSELY, N. After Habermas: new perspectives on the public sphere. Oxford, UK: Blackwell, 2004.

DAGNINO, E. Sociedade civil e espaços públicos no Brasil. São Paulo: Paz e Terra, 2002.

DEFLEM, M. Habermas, Modernity and Law. London: SAGE Publications, 1996. DEMIROVIC, A. Hegemonie und Öffentlichkeit. Das Argument, 4-5, p. 689, 1994. DEWS, Peter. Faktizität, Geltung und Öffentlichkeit. Deutsche Zeitschrift für Philosophie, v. 41, n. 2, p. 359-364, 1993.

DEWS, Peter. Habermas: a Critical Reader. Oxford, UK: Blackwell, 1999.

DUTRA, Delamar V. Razão e consenso em Habermas. Ed. UFSC, 2005.

EDER, K. Zur Transformation nationalstaatlicher Öffentlichkeit in Europa. Berliner Journal für Soziologie, n. 2, p. 167-184, 2000.

FARIAS, Fábio B. Globalização e estado cosmopolita: antinomias de Jürgen Habermas. São Paulo: Cortez, 2001.

FRASER, Nancy. Rethinking the Public Sphere: a Contribution to the Critique of the Actually Existing Democracy. In: CALHOUN, Craig. Habermas and the Public Sphere. Cambridge, MA: MIT Press, 1992. p. 109-142. 
FRASER, Nancy. Transnationalizing the public sphere. New York, 2002. Manuscrito. GERHARDS, J. et al. Four models of the public sphere in modern democracies. Theory and Society, v. 31, n. 3, p. 289-324, 2002.

GERHARDS, J.; NEIDHARDT, F. Strukturen und Funktionen moderner Öffentlichkeit. Wissenschaftszentrum Berlin. 1990.

GIESEN, K. Habermas, a segunda modernidade e a sociedade civil internacional. Novos Estudos Cebrap, São Paulo, n. 60, p. 87-96, 2001.

GOODE, Luke. Jürgen Habermas: Democracy and the Public Sphere. London: Pluto Press, 2005.

HABERMAS, Jürgen. A political constitution for pluralist world society? 2005. Manuscrito.

HABERMAS, Jürgen. Concluding comments on empirical approaches to deliberative politics. Acta Politica, International Journal of Political Science, v. 40, n. 3, p. 384392.

HABERMAS, Jürgen. Der gespaltene Westen: Kleine politische Schriften X. Frankfurt am Main: Suhrkamp, 2004.

HABERMAS, Jürgen. Die Einbeziehung des Anderen: Studien zur politischen Theorie. Frankfurt am Main: Suhrkamp, 1996.

HABERMAS, Jürgen. Die neue Unübersichtlichkeit: Kleine politische Schriften V. Frankfurt am Main: Suhrkamp, 1985.

HABERMAS, Jürgen. Die postnationale Konstellation: Politische Essays. Frankfurt am Main: Suhrkamp, 1998.

HABERMAS, Jürgen. Faktizität und Geltung. Frankfurt am Main: Suhrkamp, 1992. HABERMAS, Jürgen. Öffentlicher Raum und politische Öffentlichkeit. In: HABERMAS, Jürgen. Zwischen Naturalismus und Religion. Frankfurt am Main: Suhrkamp, 2005. p. 15-26.

HABERMAS, Jürgen. Political communication in media society. 2006. Manuscrito. HABERMAS, Jürgen. Strukturwandel der Öffentlichkeit. Frankfurt am Main: Suhrkamp, 1990. (Vorwort zur Neuauflage).

HABERMAS, Jürgen. Theorie des Kommunikativen Handelns. Frankfurt am Main: Suhrkamp, 1981.2v.

HABERMAS, Jürgen. Zeit der Übergänge: Kleine politische Schriften IX. Frankfurt am Main: Suhrkamp, 2001.

HABERMAS, Jürgen. Zwischen Naturalismus und Religion. Frankfurt am Main: Suhrkamp, 2005.

HAHN, Lewis E. Perspectives on Habermas. La Salle, Ill.: Open Court, 2000. HELD, David. Democracy and the global order. Cambridge: Polity Press, 1995. HEMING, Ralf. Öffentlichkeit, Diskurs und Gesellschaft: Zum analytischen Potential und zur Kritik des Begriffs der Öffentlichkeit bei Habermas. Wiesbaden: Deutscher Universität Verlag, 1997.

HOHENDAHL, Peter U. Öffentlichkeit, Geschichte eines kritischen Begriffs. Stuttgart: Metzler Verlag, 2000. 
HOLUB, Robert. Jürgen Habermas: Critic in the Public Sphere. London; New York: Routledge, 1991.

HONNETH, Axel et al. Zwischenbetrachtungen: Im Prozeß der Aufklärung. Frankfurt am Main: Suhrkamp, 1989.

HONNETH, Axel. Jürgen Habermas: percurso acadêmico e obra. Revista Tempo Brasileiro, n. 138, p. 9-32, 1999.

HONNETH, Axel; JOAS, Hans. Kommunikatives Handeln: Beiträge zu Jürgen Habermas “Theorie des Kommunikativen Handelns”. Frankfurt am Main: Suhrkamp, 1986.

KELLNER, D. Habermas, the Public Sphere, and Democracy: A Critical Intervention. In: HAHN, Lewis E. Perspectives on Habermas. La Salle, Ill.: Open Court, 2000.

KRAUS, P. Democracy, Communication and Language in Europe's Transnational Political Space. Berlin: Wissenschaftzentrum, 2005.

LABERENZ, L. Schöne neue Öffentlichkeit. Beiträge zu Jürgen Habermas "Strukturwandel der Öffentlichkeit". Hamburg: VSA-Verlag, 2003.

LUBENOW, J. A. A categoria de esfera pública em Jürgen Habermas. Tese (Doutorado) - Unicamp, Campinas. 2007.

LUBENOW, J. A. A despolitização da esfera pública em Habermas. In: GARCIA. Linguagem, Intersubjetividade e Ação. Ed. Unijuí, 2003. p. 273-284.

LUBENOW, J. A. A reorientação da esfera pública na 'Teoria do agir comunicativo'. Revista Ideação, 14, p. 37-59, 2005.

LUBENOW, J. A.; NEVES, R. Entre promessas e desenganos: lutas sociais, esfera pública e direito. In: NOBRE, M.; TERRA, R. Direito e democracia: um guia de leitura. São Paulo: Malheiros, 2008. p. 103-123.

McCARTHY, T. A. La Teoría Critica de Jürgen Habermas. Madri: Tecnos, 1995. MINIUCI, G. Ação Comunicativa e Relações Internacionais. Novos Estudos Cebrap, São Paulo, 73, p. 74-87, 2005.

NANZ, Patrizia I. European Community without a demos?: Rethinking conceptionsof the public sphere. Berlin: Wissenschaftszentrum, 2005.

NEGT, Oskar; KLUGE, Alexander. Öffentlichkeit und Erfahrung: zur Organisationsanalyse von bürgerlicher und proletarischer Öffentlichkeit. Frankfurt am Main: Suhrkamp, 1972.

NEIDHARDT, F. Öffentlichkeit, öffentliche Meinung, soziale Bewegung. Westdeutschland Verlag, 1994.

NOBRE, M.; COELHO, V. S. Participação e Deliberação: Teoria Democrática e Experiências Institucionais no Brasil Contemporâneo. São Paulo: Ed. 34, 2004.

NOBRE, M.; TERRA, R. Direito e democracia: um guia de leitura. São Paulo: Malheiros, 2008.

OTTMAN, Goetz. Habermas e a esfera pública no Brasil: considerações conceituais. Novos Estudos Cebrap, São Paulo, 68, p. 61-68, 2004.

OUTWHAITE, William. The Habermas Reader. Cambridge: Polity Press, 2000. 
PETERS, Bernard. Deliberative Öffentlichkeit. In: WINGERT, Lutz; GÜNTHER, Klaus. Die Öffentlichkeit der Vernunft und die Vernunft der Öffentlichkeit. Frankfurt am Main: Suhrkamp, 2001. p. 655-676.

PETERS, Bernard. Der Sinn der Öffentlichkeit.In: NEIDHARDT, F. Öffentlichkeit, öffentliche Meinung, soziale Bewegung. Westdeutschland Verlag, 1994. p. 42-76.

RAHMAN-NIAGHI, M. Die politische Implikationen der Habermas' Theorie des Kommunikativen Handelns. Dissertation. Freie Universität Berlin, 1996.

RESTORF, Mathias. Die politische Theorie von Jürgen Habermas. Marburg: Tectum, 1997.

ROSENFELD, M.; ARATO, A. Habermas on Law and Democracy. Berkeley: Univ. of California Press, 1998.

RUSH, Fred. The Cambridge Companion to Critical Theory. Cambridge: Cambridge Univ. Press, 2004.

SCHEYLI, M. Politische Öffentlichkeit und Deliberative Demokratie nach Habermas. Nomos: Verlag, 2000.

SCHUARTZ, L. F. Die Hoffnung auf radikale Demokratie: Fragen an die Theorie des Kommunikativen Handelns. Dissertation. Frankfurt Universität, 1999.

SOUZA, Jessé. A singularidade Ocidental como aprendizado reflexivo: Jürgen Habermas e o conceito de esfera pública. In: SOUZA, Jessé. A modernidade seletiva. Brasília: Ed. UnB, 2000. p. 59-93.

WHITE, Stephen. The Cambridge Companion to Habermas. Cambridge: Cambridge Press, 1997.

WINGERT, Lutz; GÜNTHER, Klaus. Die Öffentlichkeit der Vernunft und die Vernunft der Öffentlichkeit. Frankfurt am Main: Suhrkamp, 2001. 